\title{
TOWARDS A DIGITAL FACTORY - RESEARCH IN THE WORLD AND OUR COUNTRY
}

\author{
Dr Vidosav Majstorović * \\ University of Belgrade, Faculty of Mechanical Engineering, Belgrade, Serbia
}

This paper presents an analysis and synthesis of research carried out in the field of digital factory and digital manufacturing. The aim was to present different approaches and concepts, digital manufacturing and digital factory, for the purpose of establishing a common research approach. The engineering model of manufacturing based on digital models of products, processes and resources is the future of manufacturing engineering in this area, and are therefore subject to analysis in this study particularly important. At the end are particularly given to future research directions in the field of digital factory and of manufacturing.

Key words: Digital factory, Digital manufacturing, Manufacturing, Modeling, Factories

\section{INTRODUCTION}

Today's business structure is more complex and dynamic than ever before. The market requires rapid changes in the industry with new products, which directly reflects on the work of the factory. On the other hand, digitization and information technology (IT) provide new, unimagined possibilities, engineers in the design and planning. These two approaches have led to two concepts that have since emerged: the digital factory and digital manufacturing. They allow to improve the engineering product development and create a new era in business and manufacturing, where the sustainability of one of the most important factors of business [18]. Targets set in the digital factory are: to improve the manufacturing technology, reduce the costs of planning, improving the quality of manufacturing / products, and increase adaptability to new demands of customers and markets [12].

In the area of production, the words digital factory, digital manufacturing, product modeling, etc., are now widely used. What do these concepts actually mean? The answer is not simple, because the meaning of these terms depends on the views of users, their perception, application, knowledge, and much more. This requires very careful use of these terms. There are some concepts and acronyms that are related to the digital factory and digital manufacturing, which are essential to highlight. This specifically includes the definition of the concept of virtual factories and virtual manufacturing [20], the same types of problems encountered and the digital factory and digital manufacturing. Definitions of these concepts varies depending on the time of research and researchers who appointed them. The definition of virtual factory should be synonymous with the digital factory, a virtual manufacturing should be synonymous with digital manufacturing. Our research shows that we should not distinguish between the concept of virtual and digital factory / manufacturing in this area. According to [14] there are some common characteristics in the research areas of digital / virtual manufacturing, factories and enterprises. These are, for example: (a) an integrated approach to improve products, processes and technologies (integrated digital model), (b) the application of computer tools, such as modeling and simulation, planning and analysis of real technological processes, and (c) framework for the application of new technologies, including development of new methods and systems.

\section{BASICS OF THE DIGITAL FACTORY AND DIGITAL MANUFACTURING}

\section{Basic digital factory}

No universally accepted definition for the digital factory, but can give some of them: (a) on the digital factory make animated visualization and simulation, which includes: advanced methods and processes in planning, integration of software tools and a competent staff, (b) digital factory a static model that includes geometric, technical and logistics data, given as an image object. Digital Factory contains digital informa 
tion on the plant and its resources: location, media, logistics, simulation tools, and so on, [07] (c) is a generic digital factory digitized model of the factory, with its technological systems as key model from which others derive models as a mirror of the real manufacturing system. The digital factory design information (and present), evolving from the initial state of design, the final state, passing through various stages of reconfiguration. Information on manufacturing equipment and its features, tools, clamping accessories, material handling devices, etc., were also identified in the digital model. Therefore, we can say that digital information platform of factories manufacturing system in its lifetime, (d) digital factory generic term for a wide network of digital models, methods and tools, including simulation and $3 D$ visualization [17]. If we now go from the foregoing definitions, one can derive common features for the digital factory / manufacturing, [05] as: interoperability, database / knowledge, information capture and digital plant architecture. Interoperability data, together with the portability, expandability and scalability is the most important features of information models. To achieve this, the models should be in a neutral format, which provides that the models and explicit information for them, or the system is independent. One way to achieve this is to use existing standards for information modeling [10]. Database / knowledge is used to generate different models of digital factories, which are associated IT tools for modeling and performing various processes in it. The most common approach is to develop joint / unified data base for the digital factory, which develops after defining the information architecture of the digital factory. The most common option is the development of these models in a neutral format, because the information model is the core of the digital factory. In developing the information model must also be taken into account the life cycle of information, their domain, resources and processes that affect them. But the truth is here to say that the single database is not the only solution, and the second solution is a distributed database, which reduces the problems that appear errors in it. But no matter which solution is used, it is necessary to have a good information architecture and IT tools for its support. Information capture and digital plant architecture - generally speaking, digital factory planning is not only digital, but should be a database for her life. Therefore the main issue, as the its structure and organization affects an enormous amount of information that is generated and used constantly. As noted above, the digital factory is mainly used for digital planning products, processes and resources for manufacturing, and therefore for each of the elements necessary information. But here it must be noted that all of this information need not be in the digital oblku. What does it depend. The answer is that it depends on what we mean by the definition of business system, factory, manufacturing system and its operation [01]. Only when these things have clearly defined, then we can define the scope of information for our definition of a digital factory. If we look at the digital factory as a technological system, it is a product of its materialization rather than design. This means that the digital product model should not be included in a digital model of factories. But on the other hand, on (digital model of the product) must be compatible with the digital model of factories, to make it possible simulation of manufacturing. As a result, digital factory should be configured in the resource and process information. The process is a set of one or more activities related to the work process or work flow processes, the manufacturing of products in the factory itself. This manufacturing process is necessary and appropriate support: tools, accessories, transportation, maintenance, etc., because the factory can not function without them. Models of support processes provide better knowledge of them and reduce the volume of uncertain knowledge in the factory. Resources in the digital factory include: human resources (employees and their skills), physical resources such as machinery and equipment (all operating data on them) and information resources (management and administration of the factory). Processes and resources are defined in such a way to organize an information model, but that's not enough, when the plant operates on the basis of models of manufacturing activities. Because of this process and resource model should be presented so that their information domain can be modeled as an activity.

\section{BASIC DIGITAL MANUFACTURING}

Today there are real industrial plants, based on the concept of digital factory. Also, these studies deal with the load by research institutions, so the concept of digital manufacturing will be considered from two angles. From the perspective of industrial applications [15], manufacturing 
of digital computer includes support for the planning, engineering and 3D computer visualization. On the other hand in [19], the digital output is defined as a methodology that uses depth IT knowledge and technology. Profound knowledge in this model is used in digital form. CIRP dictionary, defines manufacturing as follows:" the whole of interrelated economic, technological and organizational measures, directly related to the processing of materials, ie. all functions and activities that directly contribute to the creation of goods. It includes all activities and operations relating to the product and its maintenance after manufacturing, and everything in between" [20]. In this case, the digital output of the digital factory. This definition is used by all researchers, members of the CIRP's. For example, the manufacturing model of the web-based multi agent system is defined as a digital manufacturing [07]. This concept promotes collaboration between product development and manufacturing, but different plants, using a digital model of the product.

Another example [17] proposes a model of STEP-NC manufacture, using a digital concept, which includes: (a) vane-standardized data exchange and use, (b) web communication and decision making, and (c) integration of the entire chain of manufacturing process. From the above analysis we can conclude that the volume of digital manufacturing can vary, depending on the definition that we use. Generally speaking, becomes the three most important elements that determine what is a digital manufacturing: IT system and its application, the theoretical concept of digital manufacturing - the scope of profound knowledge is used as a digital manufacturing methodologies, and using specific techniques and methods, such as for example web-based multi agent systems and the like [14, 17]. When we talk about the basic characteristics necessary information in digital manufacturing, we can say is: its digital format, multiple use and its independence of distance, time and place of use. Another aspect of digital manufacturing of its framework and the principles it uses. If we start from the principle, first defining the model, indicating that the two approaches for this purpose may be used. The first is - common denominator for simplification and abstraction of something that may not be realistic [15]. The second is - If we look at an object $B$, which is building a model, and we ask him about the object $A$, and from him (facility $B$ ) to get an answer on the object $A$ [13].
If this definition digital transfer of manufacturing, it is a virtual stock manufacturing, and these actions are performed on models of manufacturing systems and factories. Thus, the digital output should be a mirror of actual manufacturing with a few limited detail. Digital manufacturing for example uses a digital information product, you can verify the digital manufacturing through various aspects of the planning process. That's why we say that product information is extremely important in the context of various activities carried out in the factory and they'd never could be performed without them. Each product should have a digital model that can be used to simulate the benefits of digital manufacturing at the factory or for verification of different planning scenarios. All this means that the essential compatibility between digital product models and factory. The purpose of the digital output is: (a) verification through simulation facilities for manufacturing process planning, tool path and sensors for the inspection, (b) verification and performance analysis of digital manufacturing with the simulation of flow, geometry or performance machine tools. Forward the facts clearly define the scope of digital manufacturing, related to all manufacturing activities from beginning to end development of a product, where the IT system only tool to support digital manufacturing [06, 02].Digital manufacturing is performed and the analysis and simulation of digital factories, creating its model, using some or all models of the product, so that digital manufacturing includes resources and processes of the factory. This means that digital manufacturing is a way to verify the manufacturing of appropriate options for the type of product. The analysis shows that today still perform specific research in the field of digital manufacturing / factory, with no uniform definitions for these areas. For these reasons, all studies in this area of work, you need to start from the definition of digital manufacturing / factory which is used in this study.

\section{OUR RESEARCH ACTIVITIES IN DIGITAL MANUFACTURING}

Serbian as National Technology Platforms related to the Manufuture ETP was created in individual Member States and adopt the main development goals identified in both Manufuture - a vision for 2020 and the current document [11, 08, 09]. This initiatives can also encourage the emergence at regional levels of equivalent concepts promoting competitiveness by stimulation 
between sciences, education and industry in Serbia. Our national Manufuture initiatives, while adopting different models of organisation, should share the common Manufuture vision and aim to promote widening acceptance of, and participation in, Manufuture by Serbian industry, by [11, 08, 09]: (a) alerting public opinion and politicians to the challenges that Serbian manufacturing faces, as well as to industry's critical role in delivering economic output, skilled employment and sustainable growth, (b) aligning the interests of the R\&D community and technology providers in strong and effective cooperation networks that develop and source knowledge and technology, and (c) identifying and strengthening the highly competitive local networks of large companies, SME suppliers, technological partners, consultants and R\&D contractors.

The most important contributions of these Serbian initiatives should be in: (i) build a clear link to and incorporate a wide SME participation, as especially smaller SMEs can harder participate on European levels of platforms than international large companies, (ii) horizontal integration, coordination and synchronisation of R\&D efforts in Serbia, (iii) vertical application of competitive technologies, products, methods and processes in enterprises (both OEMs and SMEs) - including multidisciplinary networks coordinating R\&D activities in new industrial sectors such as medical technologies, telematics, nanotechnologies and mechatronics in EU and Serbia. Manufuture will promote successful Europe-wide implementation of solutions at various levels facilitating the structuring of effort and funding, and encouraging pan-European convergence between regional centres of industrial competitiveness [11, 08, 09]. Over the next decade, the integration of Serbia in EU will have a significant influence on European manufacturing of products for global markets. In a strategy of integration and cohesion, they could become world-class suppliers to OEMs $[11,08,09]$. This can be seen as an EU/Serbia strategy of transition, to maintain strong national/ regional sectors in the interim period, opening a competition between EU members in all areas, even in R\&D as a key factor to promote excellence and fostering the European manufacturing progresses connected to the high-added-value industrial paradigm $[10,11,08,09]$. Serbian as national initiatives will be particularly important in the new MS, such as Serbia. After many years of socialist regulation, their move towards market economy - in R\&D, as in other spheres - is a major mental, organisational, technical and financial challenge.

\section{CONCLUSIONS}

Starting from the facts stated in the text, according to some directions for research in the field of digital factories, such as: (a) establishing a single definition, scope and structure of the digital factory, (b) decomposition of the information structure of digital factories and the use of ISO 10303 standards, (c) explore suitable IT architecture that will be used for the development, transfer and use different models of digital products, processes and resources, and (d) development of an ontological concept for linking models and their structure in a digital factory. Our research is now related to the last aspect of the systemic approach to the development of digital manufacturing and digital factory [10, 11, 08, 09].

Note: This article is part of the research carried out within the Project TR 35 022, supported by the Ministry of Education and Science.

\section{REFERENCES}

1) Bley, H., Franke, C., Integration of Product Design and Assembly Planning in Digital Factory, Annals of the CIRP, 53/1:25-30, 2004.

2) Brogren, C., Implementation of a Sustainable European Manufacturing Industry, Proceedings of Manufuture Conference, Nancy, 2009.

3) CIRP, Dictionary of Production Engineering Vol.3, Manufacturing Systems 1st Edition, ISBN -540-20555-1

4) Jovane, F., Global experiences: sustainable manufacturing, Politecnico di Milano, 2010, Milano.

5) Kjellberg, T., Katz, Z., Larsson, M., The Digital Factory supporting Changeability of Manufacturing Systems, Proceedings of CIRP ISMS, pp. 102-106, 2005.

6) Lee, J., E-manufacturing - fundamental, tools, and transformation, IJ Robotics and Computer Integrated Manufacturing 19 (2008) 501-507.

7) Mahesh, M., Ong, S.K., Nee, A.Y.C., Fuh, J.Y.H., Zhang, Y.F., Towards a generic distributed and collaborative digital manufacturing, Robotics and Computer-Integrated Manufacturing, 23:267-275, 2007. 
8) Majstorovic, V., Center of Excellence for Manufacturing Engineering and Management (CEMEM) , Facts - Objectives - Goals - Researches Framework, Mechanical Engineering Faculty, Belgrade, 2008.

9) Majstorovic, V., Manufuture Serbia - Strategic Research Agenda 2008-2015, Mechanical Engineering Faculty, Belgrade, 2008.

10) Majstorovic, V., Šibalija, T., EU / Serbia Manufuture Excellence, Introduction paper, Proceedings of Manufuture Conference, $\mathrm{pp}$. 28/34, Tampere, 2007.

11) Majstorovic, V., Sibalija, T., ManuFuture \& Factories of the Future - Contribution from ManuFuture Cluster Serbia, Second Serbian's Manufuture Conference, Belgrade, 2011.

12) Mattucci, M., Factories of the Future, COMAU, EFFRA, Milano, 2010.

13) Minsky, M. L., Matter, minds and models, Proc. International Federation of Information Processing Congress, 1:45-49, 1965.

14) Nylund, H., Salminen, K., Andersson, P., Digital Virtual Holons - An Approach to Digital Manufacturing Systems, Proceedings of CIRP Conference on Manufacturing Systems, pp. 64-68, 2008.

15) Petrović, P., Milačić, V.: Nacionalne tehnološke platforme Srbije - novi formalni okvir za reinženjering industrije Srbije, (2010) Journal of Applied Engineering Science (Istraživanja i projektovanja za privredu), no. 29, p. 147-161
16) Rogstrand, V., Nielsen, J., Kjellberg, T., Integrated Information as an Enabler for Change Impact Evaluation in Manufacturing Lifecycle Management, Proceedings of CIRP Conference on Manufacturing Systems, pp. 162-166, 2008.

17) Wenzel, S., Jessen, U., Bernhard, J., Classifications and conventions structure the handling of models within the Digital Factory, Computers in Industry, 56:334-346, 2005.

18) Westkämper, E., Manufuture and Sustainable Manufacturing, Proceedings of CIRP Conference on Manufacturing Systems, pp. 20-28, 2008.

19) Westkämper, E., Strategic Development of Factories under the Influence of Emergent Technologies, Annals of the CIRP, 56/1:419422, 2007.

20) Yang, W., Xu, X., Modelling machine tool data in support of STEP-NC based manufacturing, International Journal of Computer Integrated Manufacturing, 21/7:745-763, 2008.

21) Zülch, G., Stowasser, S., The Digital Factory: An instrument of the present and future, Computer in industry, 56:323-324, 2005.

Paper sent to revision: 31.08.2012.

Paper ready for publication: 27.09.2012. 